\title{
YENI DOĞUM YAPMIŞ ANNELERIN DEPRESYON BELIRTILERI: EVLILIK DOYUMU VE DOĞUM ZORLUK DERECESININ ÖNEMI
}

\author{
Ö.Y. Alkar*, T. Gençöz ${ }^{\star \star}$
}

ÖZET:

Amaç: Bu araştırmanın amacı evlilik doyum düzeyi ile anne tarafından algılanan doğum zorluk derecesinin, erken dönem doğum sonrası depresif duygu durumu üzerindeki etkisini incelemektir. Yöntem: Araştırmaya 151 doğum sonrası dönemde olan kadın katılmıştır. Veri toplama araçları olarak, Edinburgh Postnatal Depresyon Ölçeği (EPDÖ) ve doğumla ilgili sorular kullanılmıştır. Bulgular: Çocuk sayısı kontrol edilerek yürütülen kovaryans analizi sonuçlarına göre, algılanan doğum zorluk derecesi ve evlilik doyumunun erken dönem postnatal semptomlar üzerinde temel etkisi olduğu bulunmuştur. Sonuç: Doğumlarını zor olarak algılayan ve/veya evlilik problemleri olan gruptaki kadınların erken doğum sonrası dönemde risk grubu oluşturduklarının altı çizilmiştir.

Anahtar Kelimeler: Doğum Sonrası Depresyonu, EPDÖ, Evlilik Doyumu, Algılanan Doğum Zorluk Derecesi, Kadın.

* Dr., Psikolog, SB Ankara Etlik İhtisas Hastanesi.

** Doç. Dr., Orta Doğu Teknik Üniversitesi, Psikoloji Bölümü.

\section{SUMMARY:}

Aim: The purpose of the present study was to examine marital satisfaction and perceived difficulty level of the labor in relation to early postnatal depressive mood. Method: 151 postnatal women participated in the study. They completed the Dyadic Adjustment Scale, Edinburgh Postnatal Depression Scale (EPDS), and labor related questions. Results: Results of covariance analysis that controlled for number of children revealed significant main effects of Perceived Difficulty Level of Labor and of Marital Satisfaction on early postnatal depressive symptoms. Conclusion: Results underlined that, those women who perceived their labor as difficult and/or those who had marital problems during their immediate postpartum period, constituted the risk group for developing postpartum depressive symptamatology.

Key Words: Postpartum Depression, EPDS, Marital Satisfaction, Perceived Labor difficulty, Women.

\section{GiRiş}

Doğum sonrası depresyon semptomatolojisi (DSDS) dünyanın pek çok ülkesinde önemli 
bir sağlık sorunu olarak görülmektedir (Benvenuti ve ark 1999, Bondas 2002). Doğum sonrası depresyon, ilk kez bebek sahibi olan annelerin yaklaşık \% 10-15'inde görülmektedir (Cox ve ark 1982, Kumar ve Robson 1984, Steiner 1997a). Ancak bu oran kullanılan ölçüm aracına (kendini değerlendirme ya da tanı koyma amaçlı görüşme) ya da ölçüm zamanına göre oldukça değişmektedir (Bergant ve ark 1999, Da Costa ve ark 2000, Georgiopoulus ve ark 1999, Okano ve ark 1998, Righetti-Veltema ve ark 1998 ).

Doğumdan sonraki ilk bir ayda, yeni doğum yapmış annelerde depresyon görülme riskinin iki katına çıktığı belirtilmektedir (Okano ve ark 1998). Ayrıca depresyonun ilk kez ortaya çıkışının anneliğin ilk yıllarında zirveye çıktığı belirtilmektedir (Oates 1996). Kültürlerarası yapılan bir çalışmada, annelerin üçte birinin doğumdan sonraki ilk ve ikinci haftada DSDS'nde yükselme ve yaklaşık \%22.6'sında da doğum sonrası dört ve altıncı haftalarda depresif semptomlarda artış tespit edilmiştir (Affonso ve ark 2000).

DSDS'nin olumsuz sonuçları sadece anneyi değil aynı zamanda bebek ve aileyi de etkilemektedir. Annelerin çoğunun doğum sonrası altıncı haftada depresif semptomları olduğu ve eğer tedavi edilmezse pek çok kadının doğum sonrası ilk yılın sonunda hâla depresif semptomlarını sürdürdükleri belirtilmektedir (Georgiopoulus ve ark 1999). Bu bulguyla tutarlı olarak doğum sonrası depresyonun kronikleşebileceği de gösterilmiştir (Kumar ve Robson 1984, Campbell ve ark 1992) .

Ebeveynliğe geçiş döneminde DSDS'ne eşler arasındaki sorunlar da eşlik edebilmektedir. Depresif annelerin eşleriyle olan ilişkileri incelenmiş ve çiftler arası sorunların hem hamileliğin erken dönemlerinde hem de doğumdan sonraki ilk üç ayda depresyonla ilişkili olduğu bulunmuştur (Kumar ve Robson 1984). Eşlerden birinde görülen depresif semptomlar, diğer eşin çocuk yetiştirmedeki sorumluluğunda artışa sebep olmakta (Hagen 2002) ve depresif annenin çocuğuna karşı olan davranışları da eşiyle yaşadığı çatışmalardan etkilenmektedir (Murray ve ark 1999). Ayrıca yapılan bir başka araştırmada da, doğum sonrası depresyonu olan annelerin ve eşlerinin bir yılın sonunda ebeveynlik rollerinden daha az memnun olduklarını ve bebeklerini daha zor mizaçlı olarak değerlendirdikleri bulunmuştur (Edhborg ve ark 2000). Doğum sonrası ilk yılda anne ve babanın depresyonunu etkileyen etkenlerle ilgili yapılan bir araştırmada, babanın depresyon düzeyinin, annenin kişiliğiyle ilgili sıkıntılar ve geçmiş çözümlenmemiş yaşam olaylarının yanısıra, annenin ruhsal durumu ve bebekle ilgili sorunlar ve evlilik ilişkisinin durumundan da etkilendiği belirtilmiştir (Dudley ve ark 2001). Öte yandan, eşin desteği depresif semptomlarda önemli bir azalmaya sebep olmaktadır (Misri ve ark 2000). Ülkemizde, Manisa'da, doğumdan altı ay sonra 317 anneyle yapılan bir çalışmada, annenin geçmiş psikiyatrik sorunlarının varlığının yanısıra, eşteki geçmiş psikiyatrik hastalık hikayesi, eşler arası ilişkideki sorunlar ve eşin ailesiyle yaşanan sorunların doğum sonrası depresyon görülme sıklığını etkilediği rapor edilmiştir (Danacı ve ark 2002). Bu sonuçla tutarlı olarak doğumdan bir yıl sonra 679 anneyle yapılan araştırma, annenin geçmiş psikiyatrik sorunlarının varlığı, eşle ve eşin annesiyle varolan ilişki sorunları doğum sonrası depresyonu yordayan faktörler olarak belirtilmiştir (Dindar ve ark 2007). Erzurum'da bir yıl önce doğum yapmış 728 annenin katıldığı başka bir çalışmada ise eşin işsiz olması, eşin desteğinin olmaması doğum sonrası depresyon ile ilişkili bulunmuştur (Aydın ve ark 2005).

Doğum sonrası depresyonunun olumsuz etkileri sadece annenin sosyal ve kişisel uyumuna değil aynı zamanda anne-bebek etkileşimi üzerine de olmaktadır. Doğum sonrası depresyonu, anne-bebek etkileşiminde bozulmayla ilişkilendirilmiştir (Murray ve ark 1996, Conroy ve Marks 2003) ve ileri düzeydeki psikopatolojinin güvensiz bağlanma ile ilişkili olduğu belirtil- 
miştir (Hipwell ve ark 2000). Bir başka çalışmada da doğum sonrası depresyonun güvensiz bağlanma ile ilişkili olduğu ve güvensiz bağlanmanın annenin depresyon sürecinden sonraki dönemde bile kalıcı olabileceği rapor edilmiştir (Edhborg ve ark 2001). DSDS gösteren annelerin bebeklerine karşı daha fazla olumsuz duygu ve daha az olumlu tutum sergiledikleri (Campbell ve ark 1992, Pajulo ve ark 2004) ve benzer bir biçimde de depresyonu olan annelerin 10 aylık bebeklerinin de, depresyonu olmayan annelerin bebekleriyle karşılaştırıldıklarında, daha fazla olumsuz duygu ve daha az olumlu duygu gösterdikleri rapor edilmiştir (Jones ve ark 2001). Ayrıca DSDS, bebekteki sosyo-emosyonel güçlüklerle (Murray ve ark 1999) ve çocuğun davranış problemleriyle ilişkili olduğu bulunmuştur (Beck 1999). Psikolojik etkilerinin yanısıra depresyonu olan annelerin, depresyonu olmayan annelere göre, daha seyrek olarak ve daha kısa süre bebeklerini emzirdikleri de belirtilmiştir (Field ve ark 2002).

Doğum sonrası depresyonunun etiyolojisi ile ilgili pek çok açıklayıcı model öne sürülmüştür. Steiner (1997a, 1997b) depresyonun altında yatan genetik yatkınlığa dikkat çekmiştir. Öte yandan doğum sonrası depresyonun genetik yatkınlık, hormonal değişimler ve yaşanan majör hayat olaylarının bir etkileşimi sonucu ortaya çıktığı da iddia edilmektedir (Abou-Saleh ve ark 1998, Josefsson ve ark 2002). Doğumdan sonraki ilk beş haftada doğum sonrası depresyonun çok yüksek oranlarda görülmesi sebebiyle çocuk sahibi olmanın evrensel psikosoyal stres kaynağı olabileceği de savunulmaktadır (Cox ve ark 1993).

Son zamanlarda çalışmalar psikososyal stresörlere ve annenin önceki psikiyatrik hikayesine odaklanmış; pek çok araştırmacı da değişik önem derecesinde değişik risk faktörlerini tanımlamışlardır (Bondas 2002, Righetti-Veltema ve ark 1998, Lane ve ark 1997). Johson ve ark (Johson ve ark 2001) doğum sonrası depresyon geçiren kadınların, daha önce geçirilmiş bir dep- resif dönemlerinin ya da depresyona yatkınlıklarının olduğunu ve bu problemlerin gebelik tarafından maskelenmiş olduğunu savunmuşlardır. Bu savla tutarlı bir bulgu olarak, Da Costa ve arkadaşları da (Da Costa ve ark 2000) doğum öncesi depresif duygu durumunun, doğum sonrası depresif duygu durumunu yordayan en önemli faktör olduğunu rapor etmişlerdir.

DSDS'nin obstetrik ve doğum öncesi faktörlerle olan ilişkisiyle ilgili literatür yetersiz kalmakta ve tutarlılık göstermemektedir. Clement (2001) doğum şeklinin doğum sonrası depresyonunun etiyolojisindeki rolüyle ilgili 20 çalışmayı gözden geçirmiş ancak doğum şeklinin küçük bir rolü olduğu ve bu etkinin de her çalışmada görülmediğini belirtmiştir. Öte yandan, Josefsson ve arkadaşları (Josefsson ve ark 2002) doğum ve bebekle ilgili komplikasyonların ve annenin psikiyatrik hastalıklarının DSDS'yle ilişkisi olduğunu iddia etmiştir.

Önemli olumsuz etkilerine ve tedavi intiyacının aciliyetine karşın doğum sonrası depresyon sıklıkla tespit edilememektedir. Erken doğum sonrası dönemdeki anne duygu durumunun, doğum sonrası depresyonu yordadığı düşünülmektedir (Dennis 2004, Hannah 1992, Chabrol ve Teissedre 2004). Erken doğum sonrası dönemde annenin depresif belirtilerinin farkedilmesi, daha sonra ortaya çıkabilecek doğum sonrası depresyonu engelleyebilecek, erken koruyucu ve önleyici girişimlerin uygulanması fırsatını verebilecektir. Bu doğrultuda bu araştırmanın amacı evlilik doyum düzeyinin ve anne tarafından algılanan doğum zorluk derecesinin, erken doğum sonrası depresyon belirtileri ile ilişkisini incelemektir.

\section{YÖNTEM}

\section{Katılımcılar}

Araştırmaya 151 doğum sonrası dönemde olan kadın katılmıştır. Katılımcıların yaşları 17 ve 41 arasında değişmekte olup yaş ortalamaları 24.7 ( $S S=4.81$ ) olarak belirlenmiştir. Doğan bebeklerin \%51'i erkek $(n=77), \% 47$ 'si 
kız $(\mathrm{n}=71), \% 0.7$ 'si ikizdir $(\mathrm{n}=1)$ ve annelerin $\% 1.3$ 'ü $(n=2)$ doğumdan sonra bebeklerini kaybetmiştir. Kadınların çocuk sayısı, son doğan çocuk da dahil olmak üzere, 1 ile 7 arasında değişmektedir ve bu sayının ortalaması 1.7 olarak bulunmıştur ( $S S=0.95)$. Annelerin 99.3\%'ünün ilk evlilikleri olup, \% 55'inin $(n=83)$ ilk doğum, \%78.1'inin $(n=118)$ vajinal doğum, $\% 21.9$ 'unun $(n=33)$ ise sezeryan yoluyla doğumları gerçekleşmiştir. Bu çalışma geniş amaçlı bir projenin parçasıdır ve çalışmaya katılan katılımcıların verileri doğum sonrası depresyonu araştıran farklı çalışmalarda da kullanılmıştır.

\section{Veri Toplama Araçları}

Doğum Zorluk Derecesi: Doğum zorluk derecesi 11'li Likert tipi soru kullanılarak ölçülmüştür, bu ölçümde yüksek puan daha zor doğumu göstermektedir.

Çift Uyum Ölçeği (ÇUÖ): ÇUÖ (Spanier1976) 32 maddeden oluşmaktadır ve birlikte yaşayan ya da evli olan çiftlerin eşler tarafından algılanan ilişki kalitesini ölçmektedir. Yüksek puan yüksek ilişki kalitesini göstermektedir. Fışıloğlu ve Demir (2000) ölçeğin psikometrik özelliklerini Türk örnekleminde incelemişler ve geçerlilik ve güvenilirliğini tatminkar düzeyde bulmuşlardır.

Edinburgh Postnatal Depresyon Ölçeği (EPDÖ): Bu ölçek 10 maddelik bir ölçektir ve özellikle DSDS'ni ölçmek (Cox ve ark 1987) ve risk altındaki doğum sonrası dönemdeki kadınları belirlemek amacıyla geliştirilmiştir (Beck 2001). Ölçeğin iç tutarlılığı .87 ve ikiyarım güvenirliği .88 olarak bulunmuştur (Cox ve ark 1987). Maddeler 4 puanlık likert tipi ölçek üzerinde değerlendirilmektedir ve ölçek puanı tüm maddelerden alınan puanların toplanmasıyla elde edilmektedir. Puanların ranjı 0 ve 30 arasında olup yüksek puan daha yüksek DSDS'ni göstermektedir. Ölçeğin Türkçe psikometrik özellikleri Yalçınkaya-Alkar ve Gençöz (2007) tarafından çalışılmış, güvenirlik ve geçerlik katsayıları tatminkar bulunmuştur.

\section{Işlem}

Hastane etik komitesinden ve idaresinden izin alındıktan sonra, katılım gönüllülük esasına göre yapılmış ve veri toplama araçları doğumdan hemen sonraki ilk günlerde, katılımcılara tek bir defada uygulanmıştır. Tüm veri toplama araçlarının sıralaması her bir katıımcı için rastgele düzenlenmiştir.

\section{BULGULAR}

Tablo 1'de Edinburgh Postnatal Depresyon Ölçeği (EPDÖ), algılanan doğum zorluk derecesi (ADZD), Çift Uyum Ölçeği (ÇUÖ) puanları arasındaki korelasyonlar ve bu ölçeklerin ortalama değerleri verilmiştir. Tablo 1'de görüldüğü gibi doğum sonrası depresyon arttıkça ADZD artmakta, evlilik doyumu (ÇUÖ ile ölçülmüştür) ise düşmektedir. Evlilik doyumu ve ADZD arasında ise olumsuz yönde bir ilişki görülmektedir.

Varyans analizi için, evlilik doyumu ve ADZD ölçümlerinin medyan değerleri kriter alınarak, her iki ölçüm için de yüksek ve düşük olmak üzere iki grup elde edilmiş ve bu iki değişkenin postnatal depresyon semptomları ile ilişkisi kovaryans analiziyle (ANCOVA) incelenmiştir. Bu analizde çocuk sayısı ortak değişken (covariate) olarak ele alınmıştır. Medyan değerleri kriter alınarak yapılan gruplamada, evlilik doyumu için 112 puanı kesme noktası olarak alınmış ve yüksek evlilik doyumu olan gruptaki 75 katılımcının ortalama evlilik doyumu 124.17 ( $S S=7.21$ ) olarak bulunmuş, düşük evlilik doyumu olan gruptaki 75 katılımcının ortalama evlilik doyumu ise 95.29 ( $S S=18.16$ ) olarak bulunmuştur. ADZD için ise kesme noktası 8 olarak alınmış ve ADZD yüksek olan gruptaki 74 katılımcının ortalama doğum zorluk derecesi 10.82 (SS $=0.48$ ) olarak bulunmuş, ADZD düşük olan gruptaki 77 katılımcının ise ortalama doğum zorluk derecesi $5.94(S S=1.33$ ) olarak bulunmuştur.

ANCOVA sonuçlarına göre ADZD ( $F[1$, $131]=5.50, p<.05)$ ve evlilik doyumunun $(F$ $[1,131]=5.10, p<.05)$ erken dönem postna- 
Tablo 1. Edinburgh Postnatal Depresyon Ölçeği (EPDÖ), Algılanan Doğum Zorluk Derecesi (ADZD), Çift Uyum Ölçeği (ÇUÖ) Korelasyonları.

\begin{tabular}{|l|l|l|l|}
\hline & EPDÖ & ADZD & ÇUÖ \\
\hline EPDÖ & $\begin{array}{l}12.96 \\
(5.52)\end{array}$ & $.18^{*}$ & $-.23^{* *}$ \\
\hline ADZD & & 8.30 & $-.20^{*}$ \\
\hline ÇUÖ & & $(2.65)$ & 109.73 \\
& & & $(19.99)$ \\
\hline
\end{tabular}

${ }^{*} \mathrm{p}<.05,{ }^{* *} \mathrm{p}<.001$

Not: Ortalama ve Standard Sapma Değerleri diyagonalda verilmiştir.

tal semptomlar üzerinde temel etkisi olduğu bulunmuştur. Doğumu daha zor olarak algılayan kadınlar (Ort. = 14.04 ), daha kolay olarak algılayan kadınlara (Ort. = 11.87 ) göre daha fazla postnatal depresif semptom belirtmişlerdir. Ayrıca, evlilik doyumu yüksek olan kadınlar (Ort. $=11.91$ ) düşük olan kadınlara göre (Ort. = 14.00) daha az postnatal depresif semptom belirtmişlerdir. İki değişken arasındaki etkileşim ise istatistiksel olarak anlamlı düzeyde bulunmamıştır.

\section{TARTIŞMA}

$\mathrm{Bu}$ araştırmanın amacı evlilik doyum düzeyinin ve anne tarafından algılanan doğum zorluk derecesinin, erken doğum sonrası dönem depresyon belirtileri ile ilişkisinin incelenmesidir. Çalışmanın sonucu evlilik doyumunun ve eşlerin desteğinin depresif semptomların azaltılmasındaki önemini vurgulamaktadır. Araştırma sonucu ayrıca, doğumlarını zor olarak algılayan ve/veya evlilik problemleri olan gruptaki kadınların erken doğum sonrası dönemde doğum sonrası depresif semptomlar için risk grubu oluşturduklarını destekler boyuttadır. Bu bulguyla tutarlı olarak daha önce yapılan çalışmalarda da, evlilik kalitesi ve uyumunun doğum sonrası depresyonun ortaya çıkışında önemli bir faktör olduğu gösterilmektedir (Cox ve ark 1982, Kumar ve Robson 1984, Righetti-Veltema ve ark 1998, Misri ve ark 2000, Johanson ve ark 2000). Evlilik doyum düzeyinin yanısıra, evli veya birlikte yaşayan kadınların depresyon düzeyinin evli olmayan ya da birlikte yaşamayan kadınlara göre daha düşük olduğu belirtilmiştir (Gallagher ve ark 1997). Bu sebeple doğum sonrası depresyonun potensiyel sebeplerinden biri evlilikteki uyumsuzluğun stresi olabilir, ancak bu araştırmanın deseni nedeniyle sebep sonuç ilişkisi belirlenemeyeceğinden, kadınların depresyon semptomlarının evlilikteki sorunlara katkıda bulunuyor olabileceği intimali de değerlendirilmelidir. Araştırma bulguları ayrıca, doğumlarını zor olarak algılayan ve/veya evlilik problemleri olan gruptaki kadınların doğumdan hemen sonra ayrıntılı bir psikolojik değerlendirmeye tâbi tutulması ve mümkünse doğum sonrası depresyonu önlemeye yönelik erken koruyucu ve önleyici girişimlerin uygulanması gerekliliğini vurgulamaktadır. Nitekim, bu çalışmanın da desteklediği şekilde bu gruptaki kadınlar doğum sonrası depresyon görülme 
olasılığı bakımından risk grubunu oluşturmaktadırlar.

Ancak örneklem boyutu araştırmanın genellenebilirliğini kısıtlamaktadır, bu sebeple bu alanda daha büyük bir örneklemle yapılacak çalışmalara intiyaç duyulmaktadır. Çalışmanın kesitsel bir çalışma olması da bir diğer sınırlılığıdır. Bu sebeple doğum sonrası depresyonun uzunlamasına incelenebilmesi için, daha çeşitli ölçüm araçlarıyla yapılacak ve gebelikten başlayıp doğum sonrası döneme kadar uzanacak uzunlamasına çalışmalara kuvvetle intiyaç duyulmaktadır.

\section{SONUÇ}

Sonuç olarak araştırma sonuçları klinik uygulamalara yönelik önemli ip-uçları vermektedir. Doğum sonrası depresyonu önlemeye yönelik, erken koruyucu ve önleyici girişim uygulamalarında, eşler arası doyum düzeyinin ve algılanan doğum zorluk derecesinin göz önüne alındığı, bu yaşantılara ilişkin düşünce ve duygu paylaşımlarına yer verilen etkin tedavi stratejilerinin geliştirilmesinin, doğum sonrası depresyon gelişiminin önlenmesinde önemli bir rol oynayacağı düşünülmekredir. 


\section{KAYNAKLAR}

Abou-Saleh MT, Ghubash R, Karim L ve ark (1998) Hormonal Aspects of Postpartum Depression. Psychoneuroendocrinology, 23: 465-475.

Affonso DD, De AK, Horowitz JA ve ark (2000) An International Study of Postpartum Depressive Symptamotology. J Psychosom Res, 49:207-216.

Aydın N, İnandı T, Karabulut N (2005) Depression and Associated Factors Among Women Within Their First Postnatal Year in Erzurum Province in Eastern Turkey. Women Health, 41:1-12.

Beck CT (1999) Maternal Depression and Child Behavior Problems: A Meta-Analysis. J Adv Nurs, 29: 623-629.

Beck CT (2001) Predictors of Postpartum Depression: An Update. Nurs Res, 50: 275-285.

Benvenuti P, Ferrara M, Niccolai C ve ark (1999) The Edinburgh Postnatal Depression Scale: Validation for an Italian Sample. J Affect Disord, 53: 137-141.

Bergant AM, Heim K, Ulmer H ve ark (1999) Early Postnatal Depressivemood: Associations with Dbstetric and Psychological Factors. J Psychosom Res, 46:391-394.

Bondas T (2002) Finnish Women's Experiences of Antenatal Care. Midwifery, 18: 61-78.

Campbell SB, Cohn JF, Flanagan C ve ark (1992) Course Andcorrelates of Postpartum Depression During the Transition to Parenthood. Dev Psychopathol, 4: 29-47.

Chabrol H, Teissedre F (2004) Relation Between Edinburgh Postnatal Depression Scale Scores At 2-3 Days and 4-6 Weeks Postpartum. J Reprod Infant Psyc, 22: 33-39.

Clement S (2001) Psychological Aspects of Caesarean Section. Best Pract Res Cl Ob, 15: 109126.

Conroy S, Marks MN (2003) Maternal Psychological Vulnerability and Early Infant Care In A Sample of Materially Disadvantaged Women. J Reprod Infant Psyc, 21: 7-22.

Cox JL, Connor YM, Kendell RE (1982) Prospective Study of Psychiatric Disorders of Childbirth. Br J Psychiatry, 140:111-117.
Cox JL, Holden JM, Sagovsky R (1987) Detection of Postnatal Depression: Development of the 10-Item Edinburgh Postnatal Depression Scale. BJ Psychiatry, 150:782-786.

Cox JL, Murray D, Chapman G (1993) A Controlled Study of the Onset, Duration and Prevalence of Postnatal Depression. BJ Psychiatry, 163: 27-31.

Da Costa D, Larouche J, Dritsa M ve ark (2000) Psychosocial Correlates of Prepartum and Postpartum Depressed Mood. J Affect Disord, 59:31-40.

Danacı AE, Dinç G, Deveci A ve ark (2002) Postnatal Depression in Turkey: Epidemiological and Cultural Aspects. Soc Psychiatry Psychiatr Epidemiol, 37:125-129.

Dennis CL (2004) Can we Identify Mothers At Risk for Postpartum Depression in the Immediate Postpartum Period Using the Edinburgh Postnatal Depression? J Affect Disord, 78:163-169.

Dindar I, Erdoğan S (2007) Screening of Turkish Women for Postpartum Depression Within the First Postpartum Year: The Risk Profile of A Community Sample. Public Health Nurs 24:176-83.

Dudley M, Roy K, Kelk N ve ark (2001) Psychological Correlates of Depression in Fathers and Mothers in the First Postnatal Year. J Reprod Infant Psyc,19: 187-202.

Edhborg M, Lundh W, Seimyr L ve ark (2001) The Long-Term Impact of Postnatal Depressed Mood on Mother \pm Child Interaction: A Preliminary Study. J Reprod Infant Psyc, 19: 61-71.

Edhborg M, Seimyr L, Lundh W ve ark (2000) Comparisons Betweenfamilies With A 'Depressed' Mother and Non-Depressed Mother 2 Months Postpartum. J Reprod Infant Psyc, 18: 225-238.

Engindeniz AN, Küey L, Kültür S (1997) Edinburg Doğum Sonrası Depresyon Ölçeği Türkçe Formu Geçerlilik ve Güvenilirlik Çalışması. Bahar Sempozyumları 1 Kitabı, Ankara, Psikiyatri Derneği Yayınları, s:51-52.

Field T, Hernandez M, Feijo L (2002) Breastfeeding in Depressed Mother-Infant Dyads. Early Child Dev Care, 172: 539-545.

Fışıloğlu H, Demir A (2000) Applicability of the Dyadic Adjustment Scale for Measurement of Marital 
Quality With Turkish Couples. Eur J Psychol Assess, 16:214-218.

Gallagher RW, Hobfoll SE, Ritter C ve ark (1997) Marriage, Intimate Support and Depression During Pregnancy: A Study of Inner-City Women. J Health Psychol, 4: 457-469.

Georgiopoulus AM, Bryan TL, Yawn BP ve ark (1999) Popularion-Based Screening for Postpartum Depression. ACOG Educ Bull, 93: 653-657.

Hagen EH (2002) Depression As Bargaining. Evol Hum Behav, 23:323-326.

Hannah P, Adams D, Lee A ve ark (1992) Links Between Early Post-Partum Mood and Post-Natal Depression. B J Psychiatry, 160:777-780.

Hipwell AE, Goossens FA, Melhuish EC ve ark (2000) Severe Maternal Psychopathology and InfantMother Attachment. Dev Psychopathol, 12: 157-175.

Johanson R, Chapman G, Murray D ve ark (2000) The North Staffordshire Maternity Hospital Prospective Study of Pregnancy-Associated Depression. J Psychosom Obst Gyn, 2: 93-97.

Johson N, Busfield R, Sadler L ve ark (2001) Postpartum Depression: Identification of Women at Risk. Correspondence, 163:774.

Jones NA, Field T, Fox N ve ark (2001) EEG During Different Emotions in 10-Month-Old Infants of Depressed Mothers. J Reprod Infant Psyc, 19: 295312.

Josefsson A, Angelsio L, Berg G ve ark (2002) Obstetric, Somatic, and Demographic Risk Factors for Postpartum Depressive Symptoms. ACOG Educ Bull, 99:223-238.

Kumar R, Robson KM (1984) A Prospective Study of Emotional Disorders in Childbearing Women. B J Psychiatry, 144:35-47.

Lane A, Keville R, Morris M ve ark (1997) Postnatal Depression and Elation Among Mothers and Their Partners: Prevalence and Predictors. BJ Psychiatry, 171: 550-555.

Misri S, Kostaras X, Fox D ve ark (2000) The Impact of Partner Support in the Treatment of
Postpartum Depression. Can J Psychiat, 45: 554558.

Murray L, Fiori-Cowley A, Hooper R ve ark (1996) The Impact of Postnatal Depression and Associated Adversity on Early Mother-Infant Interactions and later Infant Outcomes. Child Dev, 67:25122526.

Murray L, Sinclair D, Cooper P ve ark (1999) The Socioemotional Development of 5 Year-Old Children of Postnatally Depressed Mothers. J Child Psychol Psychiatry, 40: 1259-1271.

Oates M (1996) Psychiatric Services for Women Following Childbirth. Int Rev Psychiatr, 8: 87-99.

Okano T, Nomura J, Kumar R ve ark (1998) An Epidemiological and Clinical Investigations of Postpartum Psychiatric Illness in Japanese Mothers. J Affect Disord, 48:233-240.

Pajulo M, Savonlahti E, Sourander A ve ark (2004) Maternal Representations, Depression and Interactive Behaviour in the Postnatal Period: A Brief Report. J Reprod Infant Psyc, 2: 91-98.

Righetti-Veltema M, Conne-Perreard E, Bousquet A ve ark (1998) Risk Factors and Predictive Signs of Postpartum Depression. J Affect Disord, 49:167-180.

Spanier GB (1976) Measuring Dyadic Adjustment: A New Scale for Assessing the Quality of Marriage and Similar Dyads. J Marriage Fam, 38: 1528.

Steiner M (1997a) Depression and the Postpartum Patient. Biol Psychiatry, 42:168-169.

Steiner M (1997b) Mood Disorders with Postpartum Onset: A Family Study. Biol Psychiatry, 42:129-131.

Yakçınkaya-Alkar Ö, Gençöz T (2007) Edinburgh Postnatal Depresyon Ölçeği'nin Güvenirlik ve Geçerlik Çalışması. Değerlendirilme aşamasında makale. 